\title{
Associations between markers of respiratory morbidity in European children
}

\author{
K.L. Timonen*, J. Schwartz ${ }^{\#}$, J. Nielsen", B. Brunekreef ${ }^{+}$
}

Associations between markers of respiratory morbidity in European children. K.L. Timonen, J. Schwartz, J. Nielsen, B. Brunekreef. (C) ERS Journals Ltd 2002.

ABSTRACT: School-aged children often experience acute respiratory symptoms. In a multicentre European study, the association between chronic respiratory symptoms (reported in a questionnaire), skin-prick test results, and lung function, and the occurrence of acute respiratory morbidity, was examined among children aged 6-12 yrs with chronic respiratory symptoms.

Children with chronic respiratory symptoms, living in 10 European countries, were selected from a parent-completed questionnaire $(n=4,307)$. Atopy was measured with skin-prick tests, and lung function with spirometry. A total of $1,854(86 \%$ of those in the initial cohort) children kept a successful daily diary regarding their respiratory symptoms for 2-3 months.

In multivariate logistic regression analyses, children with asthmatic symptoms, particularly those with doctor-diagnosed asthma, had a greater risk of occurrence of lower respiratory symptoms (odds ratio (OR): 6.12; 95\% confidence interval (CI): 4.99-8.35) than children with a dry nocturnal cough as their only symptom. Atopy, particularly a positive reaction to indoor allergens, was significantly associated with occurrence of lower respiratory symptoms. For atopy the OR was $1.62(95 \% \mathrm{CI}$ : 1.34-1.96). A reduced level of maximal mid-expiratory flow was associated with an increased risk of lower respiratory symptoms, cough and phlegm. The associations were similar in Scandinavia, Central Eastern, Western and Southern Europe.

To conclude, asthmatic symptoms reported in a questionnaire, atopic status and a reduced level of maximal mid-expiratory flow were associated with the occurrence of acute respiratory symptoms, especially those of lower respiratory symptoms. Eur Respir J 2002; 19: 479-486.
*Unit of Environmental Epidemiology, National Public Health Institute, Kuopio, Finland. ${ }^{\#}$ Harvard School of Public Health, Boston, MA, USA. Dept of Occupational and Environmental Medicine, University Hospital, Lund, Sweden. "Environmental and Occupational Health Unit, University of Utrecht, Utrecht, The Netherlands.

Correspondence: B. Brunekreef, Institute for Risk Assessment Sciences, Environmental and Occupational Health Group, PO Box 80176, 3508 TD Utrecht, The Netherlands. Fax: 31302535077

E-mail: b.brunekreef@iras.uu.nl

Keywords: Atopy, children, lung function, respiratory symptom

Received: October 62000

Accepted after revision October 16 2001

This study was funded in the framework of the Commission of the European Communities Environment Programme, contracts EV5V-CT920220, CIPD-CT-92-5052 and ERBCIPDCT-93-0046. K.L. Timonen was supported by grants from The Finnish Anti-Tuberculosis Association Foundation and The Ida Montin Foundation. The Finnish, Norwegian and two Swedish centres were funded by grants from the respective Governments.
School-aged children often experience acute respiratory symptoms. However, few studies have examined the longitudinal relationship between host factors, such as atopy and lung function, and respiratory morbidity in children. Among these are the studies carried out in Southampton, UK [1, 2]. In these studies, children with either wheeze or cough were followed-up over a year, by daily diaries. The main conclusion was that, although both atopy and symptoms of wheeze were associated with respiratory morbidity, a pre-existing doctor-diagnosis of asthma was the strongest predictive factor associated with more frequent and more severe lower respiratory symptom episodes, a greater proportion of symptomatic days, and a greater overall peak flow variability.

Previously, it has been shown among children from the 10 European countries that, compared with children for whom only dry nocturnal cough was reported in the screening questionnaire, children with asthmatic symptoms had a greater diurnal and day-today variation in peak expiratory flow (PEF) during a 2-3 month follow-up. Moreover, atopy, especially positive reactions to indoor allergens, and a reduced level of lung function were also predictors of a greater variation in PEF [3]. Therefore, the aim of the present study was to investigate whether these characteristics would also be associated with occurrence of acute respiratory symptoms during a 2-3 month, daily follow-up in this population.

\section{Subjects and methods}

\section{Study locations}

The study was carried out within the framework of the Pollution Effects on Asthmatic Children in 
Europe (PEACE) project, which looks at the effects of air pollution on respiratory health of children. A total of 14 study centres in 10 countries took part in this European collaboration. The participating centres were, by the location of the urban area, Amsterdam (the Netherlands), Kuopio (Finland), Oslo (Norway), Berlin and Hettstedt (Germany), Pisa (Italy), Athens (Greece), Cracow and Katowice (Poland), Prague and Teplice (Czech Republic), Budapest (Hungary), Umeå and Malmö (Sweden). In each centre, the same study protocol was followed [4, 5]. However, in Hettstedt, a different screening questionnaire was used for selection of subjects. Therefore, in the present analyses, data from 13 study centres are used, excluding Hettstedt.

\section{Study design}

In each centre there were two panels of children with chronic respiratory symptoms: an urban and a suburban, or rural, panel. The children were selected by a screening questionnaire that was completed by the parents of the child. During autumn 1993 and winter 1994, the children were characterized with skinprick tests and spirometric lung function measurements. During winter 1993-1994, the children kept, with the help of their parents, a daily diary on respiratory symptoms, and measured PEF every morning and evening for 3 months $[4,5]$.

\section{Subjects}

Of a total of 4,307 children aged 6-12 yrs eligible to enter the study and asked to participate, 2,112 (49\%) children were characterized with skin-prick test and spirometric lung function measurements. A total of 2,152 children started keeping the diary on respiratory symptoms and measuring daily PEF. Of these, 1,854 $(86 \%)$ children had valid symptoms and PEF data on more than $60 \%$ of the days, and these children were included in the present analyses (table 1). A total of $30 \%$ of the children had complete diary data, and $55 \%$ of the children had data on $80-99 \%$ of the days. A detailed description of the panels has been published previously [3].

\section{Screening questionnaire}

The screening questionnaire used in the PEACE study has been described previously $[4,5]$. A child was considered as eligible to enter the study if there was a positive response to at least one of the following questions: Has your child been bothered in the past 12 months by a wheezy chest, apart from colds? Has your child been bothered in the past 12 months by an attack of shortness of breath with wheezing? Has your child had dry cough at night in the past 12 months, apart from coughing with a cold or chest infection? Has a doctor ever said your child had asthma? [4, 5].

\section{Skin-prick tests}

In all centres, skin-prick tests were done using the ALK skin-prick test allergen panel (ALK Laboratories, Horsholm, Denmark). The allergens tested in all centres were birch (Betula verrucosa) and timothy grass (Pheleum pratense) pollens, cat fur (Felis catus), and house dust mite (Dermatophagoides pteronyssinus)

Table 1.-Description of the panels in the 13 study centres in four European regions

\begin{tabular}{|c|c|c|c|c|c|c|c|c|}
\hline & \multirow[t]{2}{*}{$\begin{array}{l}\text { Subjects } \\
\mathrm{n}\end{array}$} & \multirow[t]{2}{*}{ Females } & \multirow[t]{2}{*}{$\begin{array}{l}\text { Mean } \\
\text { age yrs }\end{array}$} & \multirow[t]{2}{*}{ Atopic } & \multicolumn{4}{|c|}{$\begin{array}{l}\text { Median (25th-75th percentile) proportion } \\
\text { of days with symptoms in the diary }\end{array}$} \\
\hline & & & & & $\begin{array}{l}\text { Lower } \\
\text { respiratory } \\
\text { symptoms }\end{array}$ & $\begin{array}{l}\text { Upper } \\
\text { respiratory } \\
\text { symptoms }\end{array}$ & Cough & Phlegm \\
\hline \multicolumn{9}{|l|}{ Scandinavia } \\
\hline Finland/Kuopio & 169 & 45 & 9.9 & 61 & $0(0-2.0)$ & $29(14-60)$ & $25(13-43)$ & $5.3(0-16)$ \\
\hline Sweden/Umeå & 147 & 40 & 9.0 & 58 & $1.2(0-7.0)$ & $18(6.7-37)$ & $11(2.5-29)$ & $0(0-8.8)$ \\
\hline Sweden/Malmö & 160 & 47 & 10.1 & 53 & $0(0-3.9)$ & $22(10-39)$ & $16(2.1-35)$ & $1.7(0-8.8)$ \\
\hline Norway/Oslo & 123 & 48 & 9.7 & 46 & $1.6(0-9.7)$ & $25(12-55)$ & $23(6.7-46)$ & $4.5(0-16)$ \\
\hline \multicolumn{9}{|l|}{ Central Eastern Europe } \\
\hline Poland/Cracow & 137 & 40 & 9.3 & 33 & $0(0-7.1)$ & $33(13-66)$ & $23(9.9-47)$ & $0(0-11)$ \\
\hline Poland/Katowice & 144 & 42 & 9.7 & 39 & $0(0-7.8)$ & $26(12-51)$ & $21(8.2-39)$ & $10(1.3-32)$ \\
\hline Czech Republic/Prague & 134 & 40 & 9.9 & 65 & $1.6(0-8.2)$ & $28(14-51)$ & $27(8.6-49)$ & $7.9(0-18)$ \\
\hline Czech Republic/Teplice & 168 & 50 & 9.8 & 21 & $0(0-1.7)$ & $16(7.9-31)$ & $20(6.3-35)$ & $0(0-9.5)$ \\
\hline Hungary/Budapest & 139 & 43 & 9.1 & 49 & $0(0-3.8)$ & $18(8.8-34)$ & $21(9.7-36)$ & $0(0-5.2)$ \\
\hline \multicolumn{9}{|l|}{ Western Europe } \\
\hline Germany/Berlin & 112 & 52 & 9.8 & 61 & $0(0-13)$ & $22(8.2-42)$ & $19(3.4-36)$ & $0(0-5.4)$ \\
\hline The Netherlands/Amsterdam & 126 & 50 & 9.7 & 46 & $0(0-5.1)$ & $24(15-55)$ & $25(13-43)$ & $6.1(0-23)$ \\
\hline \multicolumn{9}{|l|}{ Southern Europe } \\
\hline Italy/Pisa & 128 & 39 & 8.6 & 70 & $3.6(0-15)$ & $17(7.4-46)$ & $15(3.8-32)$ & $6.1(0-16)$ \\
\hline Greece/Athens & 167 & 45 & 9.0 & 19 & $0(0-5.2)$ & $17(5.6-33)$ & $16(3.5-34)$ & $3.5(0-19)$ \\
\hline
\end{tabular}

Data are presented as percentages unless otherwise stated. ${ }^{*}$ : shortness of breath, wheeze, or attacks of shortness of breath with wheezing; ${ }^{\uparrow}$ : sore throat, or runny or stuffed nose. 
$[4,5]$. Histamine hydrochloride $\left(10 \mathrm{mg} \cdot \mathrm{mL}^{-1}\right)$ and glycerol $(50 \%)$ were used as positive and negative controls, respectively. In addition, two local allergens were tested in each centre: dog epithelial dander and Cladosporium in Amsterdam, Oslo, Umeå and Malmö, dog epithelial dander and mugwort pollen in Kuopio, alternaria and plantago in Berlin, alternaria and ragweed in Budapest, alternaria and parietaria in Pisa, olive and parietaria in Athens, grass mix pollens and dog epithelial dander in Cracow and Katowice, and grass mix pollens and mould mix in Prague and Teplice. A mean weal diameter of $>2 \mathrm{~mm}$ was regarded as a positive result $[4,5]$. If there was no reaction to the positive control or a reaction $>1 \mathrm{~mm}$ to the negative control, the results were excluded from the analyses $(n=121)$.

\section{Lung function tests}

The spirometric lung function measurements were performed according to the recommendations of the European Community for Coal and Steel [4-6]. All spirometric results were corrected to body temperature, atmospheric pressure and saturation with water vapour. Predicted values based on sex and height of the subjects were calculated according to Zapletal (see [7]).

\section{Symptom diaries}

The children were followed-up for 2-3 months during winter 1993-1994. They kept a daily diary on respiratory symptoms with the help of their parents. The following symptoms were reported: cough, phlegm, runny or stuffed nose, shortness of breath, wheeze, $\operatorname{attack}(\mathrm{s})$ of shortness of breath with wheeze, and sore throat. In addition, the children measured their PEF rate every morning and evening [4, 5]. Results of PEF measurements have been published elsewhere [3].

\section{Definitions}

Children who had suffered from wheezing or attacks of shortness of breath with wheezing during the previous 12 months were defined as having "asthmatic symptoms". Children who had either these asthmatic symptoms and/or doctor-diagnosed asthma were defined as having "asthma". Children who did not have "asthma", but who had reported dry cough at night that was not associated with colds, were defined as having "cough alone". "Atopy" was defined as having at least one positive reaction in skinprick tests. "Lower respiratory symptom" was defined as being present when the child reported in the diary, on a given day to have at least one of the following symptoms: shortness of breath, wheeze, or attacks of shortness of breath with wheeze. "Upper respiratory symptom" was defined as being present when the child reported in the diary to have a sore throat, or a runny or stuffed nose.

To study possible area differences within Europe, four regions were defined. The Finnish, Swedish and
Norwegian centres formed "Scandinavia", the Polish, Czech and Hungarian centres formed "Central Eastern Europe", the German and Dutch centres formed "Western Europe", and the Italian and Greek centres formed "Southern Europe".

\section{Statistical analyses}

For each child, the proportion of the days a symptom was reported to be present was calculated from the total number of days on which there was a valid report for that symptom. Days with a missing value for the symptom were excluded from the total number of days. Multivariate logistic regression analyses were performed using the GENMOD procedure, which allowed for the calculation of an overor under-dispersion parameter, and incorporation of it in the estimation of the standard errors of the variables [8].

In all models, adjustments were made for sex, age and study centre. In addition, when studying the effects of chronic respiratory symptoms reported in the screening questionnaire, adjustments were also made for atopy and level of lung function as maximal mid-expiratory flow (MMEF) (\% from predicted). Similarly, when studying the effects of skin-prick test results, the models were also adjusted for chronic symptom status (having asthma or not) and level of lung function. Reactivity to house dust mite, cat and pollen allergens were included in the statistical model at the same time, to study the independent effects of these allergens. When studying the effects of spirometric lung function, adjustments were also made for atopy and chronic symptom status. The results are given as odds ratios (OR) with $95 \%$ confidence intervals $(\mathrm{CI})$.

\section{Results}

The mean \pm SD total number of follow-up days was $61.5 \pm 12.3$ among children with cough alone and $63.0 \pm 12.4$ among children with asthma. A total of $566(31 \%)$ children had dry nocturnal cough apart from colds as their only chronic respiratory symptom (table 2). Of the children 59\% with asthma had also had dry nocturnal cough in the past 12 months.

Compared to children with cough alone, children with asthma especially those with both symptoms and a doctor-diagnosis of asthma, more often reported all of the acute respiratory symptoms in the diary (table 2). The greatest OR was observed for lower respiratory symptoms. The difference was lowest in the occurrence of cough. Among the children with asthma, the children with asthmatic symptoms but without a diagnosis of asthma, were more likely to experience acute lower respiratory symptoms than the children with a doctor-diagnosis of asthma but without asthmatic symptoms. However, both these groups were less likely to have acute respiratory symptoms than children with both asthmatic symptoms and a diagnosis of asthma. These differences between the groups were observed in all four regions (table 3 ). 
Table 2. - Association between chronic respiratory symptoms reported in a screening questionnaire, skin-prick test results and proportion of days with respiratory symptoms present during a 2-3-month follow-up among children with chronic respiratory symptoms

\begin{tabular}{|c|c|c|c|c|c|c|c|c|c|}
\hline & \multirow[t]{2}{*}{$\begin{array}{l}\text { Subjects } \\
\text { n }\end{array}$} & \multicolumn{2}{|c|}{$\begin{array}{l}\text { Lower } \\
\text { respiratory } \\
\text { symptoms }\end{array}$} & \multicolumn{2}{|c|}{$\begin{array}{l}\text { Upper } \\
\text { respiratory } \\
\text { symptoms }\end{array}$} & \multicolumn{2}{|r|}{ Cough } & \multicolumn{2}{|c|}{ Phlegm } \\
\hline & & $\begin{array}{c}\text { Days } \\
\%\end{array}$ & $\begin{array}{c}\text { OR } \\
(95 \% \mathrm{CI})\end{array}$ & $\begin{array}{c}\text { Days } \\
\%\end{array}$ & $\begin{array}{c}\text { OR } \\
(95 \% \mathrm{CI})\end{array}$ & $\underset{\%}{\text { Days }}$ & $\begin{array}{c}\text { OR } \\
(95 \% \mathrm{CI})\end{array}$ & $\underset{\%}{\text { Days }}$ & $\begin{array}{c}\text { OR } \\
(95 \% \mathrm{CI})\end{array}$ \\
\hline \multicolumn{10}{|l|}{ Chronic respiratory symptom $^{+}$} \\
\hline Cough alone & 566 & 2.2 & 1.0 & 27.5 & 1.0 & 25.4 & 1.0 & 9.3 & 1.0 \\
\hline $\mathrm{AS}^{\S}$ and/or diagnosed asthma & 1258 & 9.1 & $\begin{array}{c}3.54 \\
(2.63-4.76)\end{array}$ & 31.9 & $\begin{array}{c}1.30 \\
(1.12-1.52)\end{array}$ & 26.4 & $\begin{array}{c}1.11 \\
(0.95-1.29)\end{array}$ & 12.5 & $\begin{array}{c}1.37 \\
(1.13-1.67)\end{array}$ \\
\hline AS and no diagnosed asthma & 489 & 6.8 & $\begin{array}{c}2.86 \\
(2.08-3.94)\end{array}$ & 32.4 & $\begin{array}{c}1.32 \\
(1.10-1.57)\end{array}$ & 26.6 & $\begin{array}{c}1.06 \\
(0.89-1.27)\end{array}$ & 12.5 & $\begin{array}{c}1.31 \\
(1.04-1.65)\end{array}$ \\
\hline No AS and diagnosed asthma & 248 & 4.1 & $\begin{array}{c}1.76 \\
(1.18-2.61)\end{array}$ & 28.0 & $\begin{array}{c}1.17 \\
(0.94-1.46)\end{array}$ & 23.8 & $\begin{array}{c}1.05 \\
(0.84-1.31)\end{array}$ & 10.5 & $\begin{array}{c}1.29 \\
(0.97-1.70)\end{array}$ \\
\hline AS and diagnosed asthma & 503 & 13.8 & $\begin{array}{c}6.12 \\
(4.49-8.35)\end{array}$ & 33.6 & $\begin{array}{c}1.40 \\
(1.16-1.69)\end{array}$ & 27.8 & $\begin{array}{c}1.26 \\
(1.04-1.53)\end{array}$ & 13.6 & $\begin{array}{c}1.59 \\
(1.25-2.02)\end{array}$ \\
\hline \multicolumn{10}{|l|}{ Atopy $^{f, \# \#}$} \\
\hline No & 914 & 4.7 & 1.0 & 28.6 & 1.0 & 26.4 & 1.0 & 11.2 & 1.0 \\
\hline Yes & 818 & 9.1 & $\begin{array}{c}1.62 \\
(1.34-1.96)\end{array}$ & 32.5 & $\begin{array}{c}1.09 \\
(0.95-1.25)\end{array}$ & 25.9 & $\begin{array}{c}0.96 \\
(0.83-1.10)\end{array}$ & 12.0 & $\begin{array}{c}1.03 \\
(0.87-1.22)\end{array}$ \\
\hline \multicolumn{10}{|l|}{ PR to house dust mite ${ }^{\text {था }}$} \\
\hline No & 1422 & 5.6 & 1.0 & 29.0 & 1.0 & 25.4 & 1.0 & 10.7 & 1.0 \\
\hline Yes & 309 & 12.5 & $\begin{array}{c}1.78 \\
(1.43-2.23)\end{array}$ & 37.0 & $\begin{array}{c}1.36 \\
(1.13-1.64)\end{array}$ & 29.5 & $\begin{array}{c}1.16 \\
(0.96-1.40)\end{array}$ & 15.7 & $\begin{array}{c}1.45 \\
(1.16-1.81)\end{array}$ \\
\hline \multicolumn{10}{|l|}{ PR to cat ${ }^{\text {था }}$} \\
\hline No & 1318 & 5.4 & 1.0 & 29.5 & 1.0 & 26.0 & 1.0 & 11.3 & 1.0 \\
\hline Yes & 414 & 11.2 & $\begin{array}{c}1.64 \\
(1.34-2.01)\end{array}$ & 33.4 & $\begin{array}{c}1.05 \\
(0.88-1.24)\end{array}$ & 26.6 & $\begin{array}{c}1.06 \\
(0.89-1.26)\end{array}$ & 12.7 & $\begin{array}{c}1.16 \\
(0.94-1.44)\end{array}$ \\
\hline \multicolumn{10}{|l|}{ PR to timothy or birch pollen } \\
\hline No & 1244 & 6.0 & 1.0 & 29.2 & 1.0 & 26.1 & 1.0 & 11.6 & 1.0 \\
\hline Yes & 486 & 9.0 & $\begin{array}{c}1.02 \\
(0.84-1.25)\end{array}$ & 33.6 & $\begin{array}{c}1.10 \\
(0.94-1.28)\end{array}$ & 26.2 & $\begin{array}{c}1.00 \\
(0.85-1.17)\end{array}$ & 11.7 & $\begin{array}{c}0.93 \\
(0.76-1.14)\end{array}$ \\
\hline
\end{tabular}

OR: odds ratio; CI: confidence interval; AS: asthmatic symptoms; PR: positive reaction. \#: shortness of breath, wheeze, or attacks of shortness of breath with wheeze; ${ }^{\uparrow}$ : stuffed/runny nose, sore throat; ${ }^{+}$: statistical model adjusted for age, sex, atopy, study centre, and level of maximal mid-expiratory flow as \% from predicted; ${ }^{\S}$ : during the past 12 months wheezing or attacks of shortness of breath with wheezing; ${ }^{f}$ : defined as at least one positive reaction in skin-prick tests; ${ }^{\# \#}$ : statistical model adjusted for age, sex, symptom status (having asthma or not), study centre, and level of maximal mid-expiratory flow as \% from predicted; ": reactivity to house dust mite, cat and pollen at the same time in the statistical model. The model adjusted also for age, sex, symptom status (having asthma or not), study centre, and level of maximal mid-expiratory flow as $\%$ from predicted.

The proportion of days with respiratory symptoms, especially with lower respiratory symptoms, rose as the number of symptoms reported in the screening questionnaire increased (fig. 1).

Atopy was significantly associated with an increased risk of lower respiratory symptoms, but not with upper respiratory symptoms, cough or phlegm (table 2). Positive reactions to indoor allergens (house dust mite, cat) were independently associated not only with lower respiratory symptoms, but also with the occurrence of upper respiratory symptoms and phlegm. In all four regions, positive reactions to indoor allergens were significant predictors of occurrence of lower respiratory symptoms (table 3).

The risk of lower respiratory symptoms rose as the number of positive reactions in the skin-prick test increased (fig. 2). The relationship between the number of positive reactions in the skin-prick test and other symptoms was less strong.

In spirometric lung function measurements, a reduced level of MMEF was most strongly associated with acute respiratory symptoms reported in the diary (table 4). This association was observed in all four regions. A low level of forced expiratory volume in one second (FEV1)/forced vital capacity (FVC) was also associated with an increased risk of lower respiratory symptoms and phlegm. A reduced level of FEV1 was significantly associated with an increased risk of phlegm. There was no clear pattern in the association between FVC and the risk of acute respiratory symptoms. The level of spirometric lung function was not associated with upper respiratory symptoms.

\section{Discussion}

In this large epidemiological multicentre study among European children with chronic respiratory symptoms, chronic respiratory symptoms reported in a screening questionnaire, atopy and level of spirometric lung function were all independently associated 
Table 3. - Association between chronic respiratory symptoms reported in a screening questionnaire, reactivity to house dust mite and cat allergens in skin-prick tests and proportion of days with lower respiratory symptoms present during a 2-3-month follow-up among children with chronic respiratory symptoms in four European regions

\begin{tabular}{|c|c|c|c|c|c|c|c|c|c|c|c|}
\hline \multicolumn{3}{|c|}{ Scandinavia } & \multicolumn{3}{|c|}{ Central Eastern Europe } & \multicolumn{3}{|c|}{ Western Europe } & \multicolumn{3}{|c|}{ Southern Europe } \\
\hline $\mathrm{n}$ & $\begin{array}{l}\% \text { of } \\
\text { days }\end{array}$ & $\begin{array}{c}\text { OR } \\
(95 \% \mathrm{CI})\end{array}$ & $\mathrm{n}$ & $\begin{array}{l}\% \text { of } \\
\text { days }\end{array}$ & $\begin{array}{c}\text { OR } \\
(95 \% \mathrm{CI})\end{array}$ & $\mathrm{n}$ & $\begin{array}{l}\% \text { of } \\
\text { days }\end{array}$ & $\begin{array}{c}\text { OR } \\
(95 \% \mathrm{CI})\end{array}$ & $\mathrm{n}$ & $\begin{array}{l}\% \text { of } \\
\text { days }\end{array}$ & $\begin{array}{c}\text { OR } \\
(95 \% \mathrm{CI})\end{array}$ \\
\hline
\end{tabular}

\begin{tabular}{|c|c|c|c|c|c|c|c|c|c|c|c|c|}
\hline \multicolumn{13}{|l|}{$\begin{array}{l}\text { Chronic respiratory } \\
\text { symptom }^{\#}\end{array}$} \\
\hline Cough alone & 209 & 2.6 & 1.0 & 228 & 2.1 & 1.0 & 54 & 1.1 & 1.0 & 75 & 1.6 & 1.0 \\
\hline AS and/or DA & 386 & 8.5 & $\begin{array}{c}2.94 \\
(1.83-4.71)\end{array}$ & 479 & 7.9 & $\begin{array}{c}3.09 \\
(2.01-4.75)\end{array}$ & 180 & 12.8 & $\begin{array}{c}7.68 \\
(2.20-26.7)\end{array}$ & 213 & 9.7 & $\begin{array}{c}6.19 \\
(2.26-16.9)\end{array}$ \\
\hline $\mathrm{AS}$ and no DA & 120 & 6.6 & $\begin{array}{c}2.38 \\
(1.38-4.09)\end{array}$ & 269 & 6.8 & $\begin{array}{c}2.69 \\
(1.71-4.22)\end{array}$ & 52 & 6.1 & $\begin{array}{c}4.42 \\
(1.20-16.3)\end{array}$ & 48 & 8.0 & $\begin{array}{c}6.06 \\
(2.05-17.9)\end{array}$ \\
\hline No AS and DA & 86 & 2.1 & $\begin{array}{c}0.74 \\
(0.34-1.59)\end{array}$ & 72 & 4.8 & $\begin{array}{c}1.92 \\
(1.03-3.60)\end{array}$ & 43 & 4.4 & $\begin{array}{c}4.48 \\
(1.14-17.5)\end{array}$ & 47 & 6.4 & $\begin{array}{c}5.40 \\
(1.78-16.4)\end{array}$ \\
\hline $\mathrm{AS}$ and $\mathrm{DA}$ & 175 & 12.8 & $\begin{array}{c}5.03 \\
(3.12-8.12)\end{array}$ & 135 & 11.7 & $\begin{array}{c}5.12 \\
(3.25-8.19)\end{array}$ & 82 & 21.7 & $\begin{array}{c}14.1 \\
(4.12-48.4)\end{array}$ & 111 & 12.3 & $\begin{array}{c}9.02 \\
(3.07-26.5)\end{array}$ \\
\hline \multicolumn{13}{|l|}{$\begin{array}{l}\text { PR to house } \\
\text { dust mite }\end{array}$} \\
\hline No & 529 & 6.3 & 1.0 & 561 & 4.7 & 1.0 & 149 & 6.4 & 1.0 & 183 & 5.4 & 1.0 \\
\hline Yes & 41 & 8.9 & $\begin{array}{c}1.40 \\
(0.79-2.48)\end{array}$ & 107 & 10.5 & $\begin{array}{c}1.89 \\
(1.35-2.65)\end{array}$ & 77 & 16.4 & $\begin{array}{c}2.10 \\
(1.21-3.65)\end{array}$ & 84 & 13.1 & $\begin{array}{c}1.60 \\
(0.88-2.88)\end{array}$ \\
\hline PR to $\mathrm{cat}^{+}$ & & 5 & 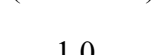 & 566 & $52+3$ & & 157 & 55 & 1 & 224 & 6 & \\
\hline Yes & 200 & 8.9 & $\begin{array}{c}1.76 \\
(1.24-2.50)\end{array}$ & 102 & 7.9 & $\begin{array}{c}1.03 \\
(0.71-1.48)\end{array}$ & 69 & 19.7 & $\begin{array}{c}2.79 \\
(1.60-4.81)\end{array}$ & 43 & 15.3 & $\begin{array}{c}1.72 \\
(0.95-3.13)\end{array}$ \\
\hline
\end{tabular}

OR: odds ratio; CI: confidence interval; AS: asthmatic symptoms; DA: diagnosed asthma; PR: positive reaction. ${ }^{\#}$ : statistical model adjusted for age, sex, atopy, study centre and level of maximal mid-expiratory flow as $\%$ from predicted; ${ }^{\uparrow}$ : during the past 12 months wheezing or attacks of shortness of breath with wheezing; ${ }^{+}:$reactivity to house dust mite, cat and pollen at the same time in the statistical model. The model adjusted also for age, sex, symptom status (having asthma or not), study centre, and level of maximal mid-expiratory flow as $\%$ from predicted.

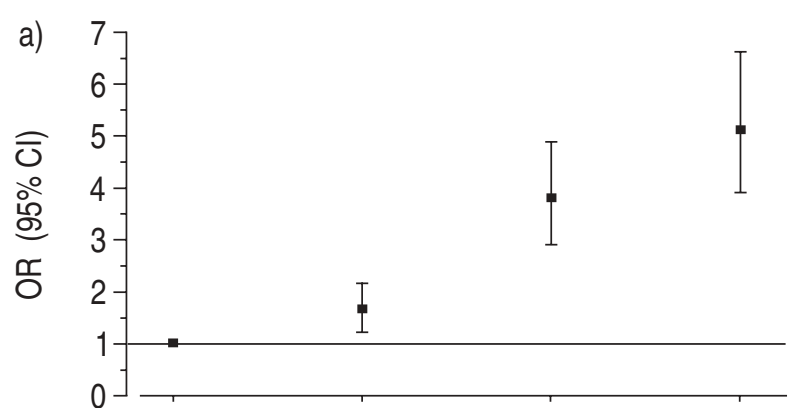

b)
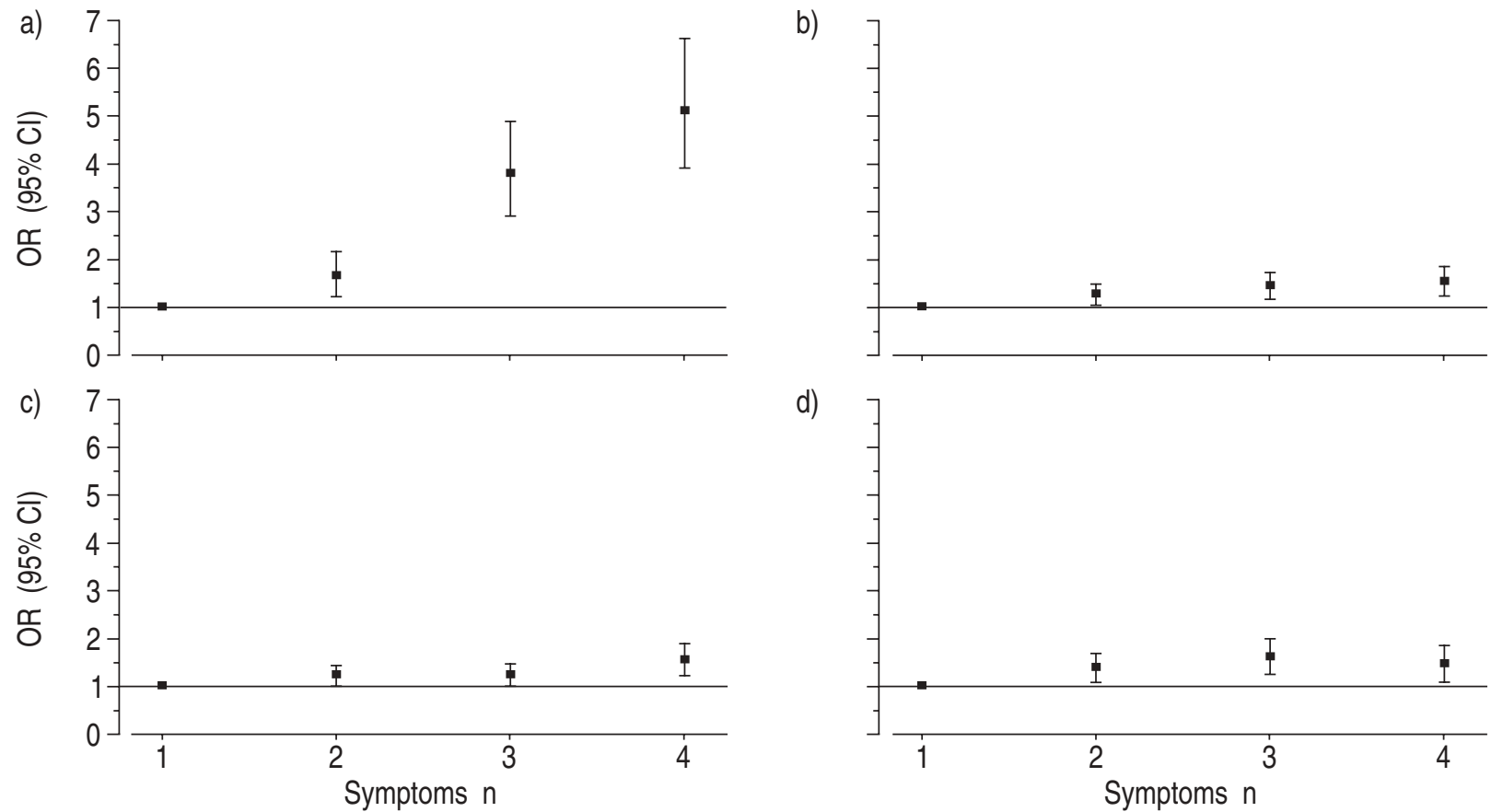

Fig. 1.-Association between the number of chronic respiratory symptoms reported in the screening questionnaire and occurrence of a) lower respiratory symptoms, b) upper respiratory symptoms, c) cough and d) phlegm during a 2-3 month follow-up. Odds ratios (OR) indicated by the solid horizontal lines at 1.0, and 95\% confidence intervals (CI) are shown. 

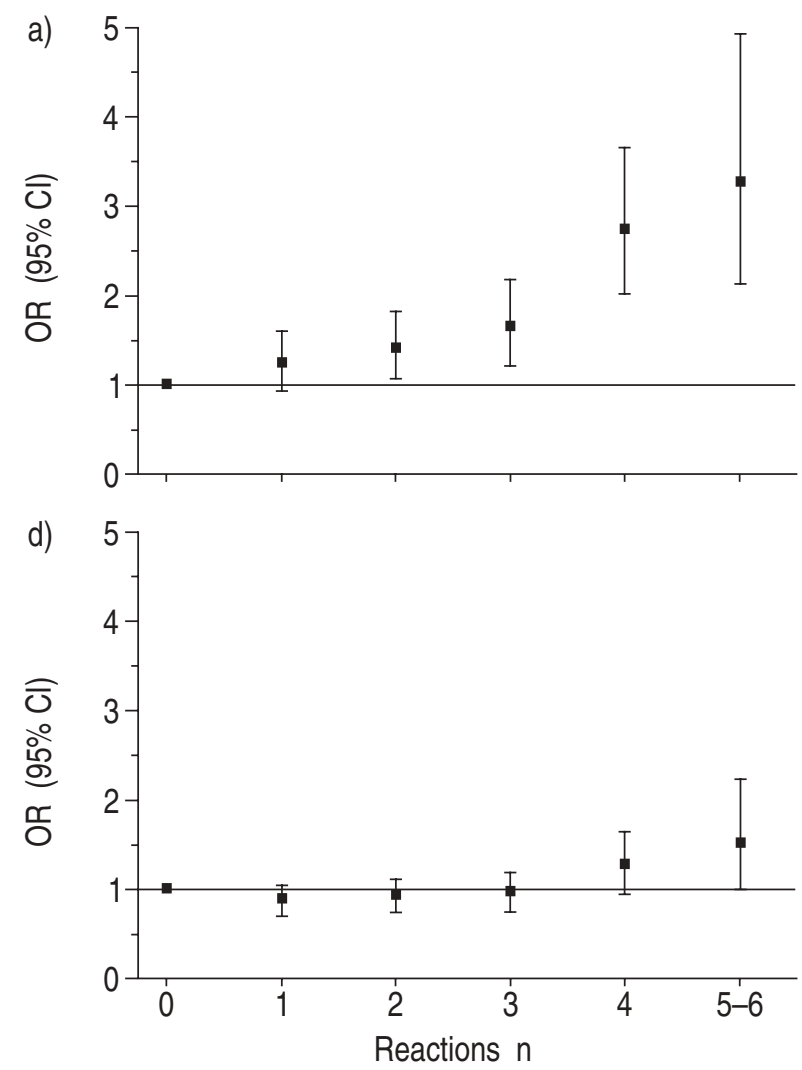

b)

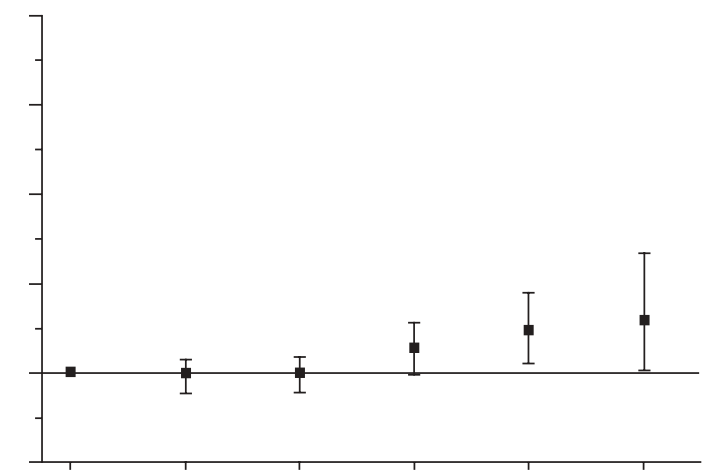

d)

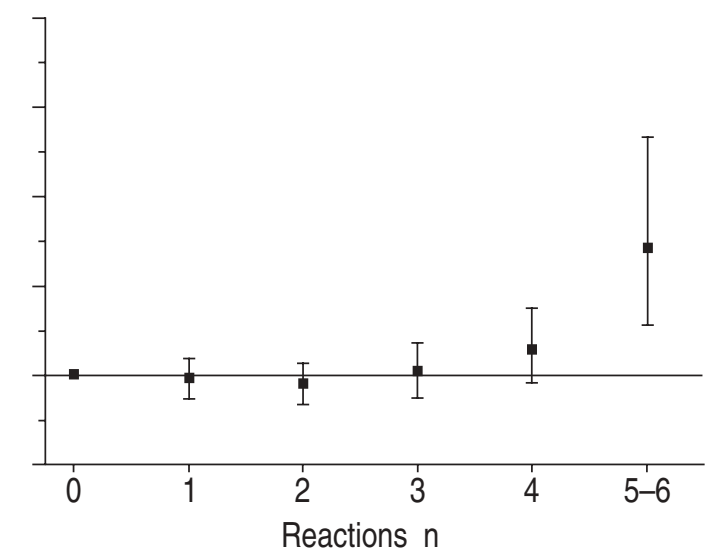

Fig. 2.-Association between the number of positive reactions in skin-prick tests and occurrence of a) lower respiratory symptoms, b) upper respiratory symptoms, c) cough and d) phlegm during a 2-3 month follow-up. Odds ratios (OR), indicated by the horizontal lines at 1.0 , and $95 \%$ confidence intervals (CI) are shown.

with the proportion of days when acute respiratory symptoms, especially lower respiratory symptoms, were reported in a daily diary during a 2-3-month follow up. A doctor-diagnosed asthma with asthmatic symptoms during the past 12 months, positive reactions to indoor allergens (house dust mite or cat) and a reduced level of MMEF were most strongly associated with the occurrence of lower respiratory symptoms. The associations were similar in Scandinavia, Central Eastern, Western and Southern Europe.

The effect estimates in the present study, however, may be too small. This is because, in the statistical models used, there were always variables for prior symptom status, level of lung function and reactivity to skin-prick tests. These factors are not, however, independent of each other. Therefore, by having all of these factors controlled for, the effects could have been underestimated.

Chronic respiratory symptoms reported in the screening questionnaire were associated with the occurrence of acute respiratory symptoms during the 2-3 month, daily follow-up, especially the occurrence of lower respiratory symptoms. Compared to children with cough alone, children with asthma experienced lower and upper respiratory symptoms, and phlegm more often. The difference in reported cough during the follow-up was not so clear. Only children with both asthmatic symptoms during the past 12 months and doctor-diagnosed asthma reported cough more often than children with cough alone. In contrast to the study by PATTEMORE et al. [2], recent asthmatic symptoms were a better predictor of acute symptoms than a doctor's diagnosis of asthma. However, children with both the diagnosis and asthmatic symptoms experienced acute respiratory symptoms most often.

A similar pattern for the occurrence of respiratory symptoms has been observed in previous studies. PEAT et al. [9] initially studied a cohort of children with current asthma, wheeze only, or who were normal. Current asthma was defined as having both recent wheeze, assessed by a questionnaire, and bronchial hyperresponsiveness, assessed by a histamine challenge test. During the follow-up over a year, most children $(93 \%)$ in the group of current asthma had wheeze, which was clearly more than among children in the wheeze-only group $(52 \%)$. However, the latter group demonstrated more wheeze than the children in the normal group (18\%). Among 650 children followed-up prospectively for 2 yrs. Children for whom current persistent wheeze was reported at the initial interview experienced more lower respiratory illness than children without current persistent wheeze at the initial interview [10]. In contrast, no significant difference was found for upper respiratory illness. Clough et al. [1] studied children with wheeze or cough only, and with or without atopy. The symptom of wheeze was associated with a significantly greater severity of acute respiratory symptoms, but not with a greater proportion of days with lower respiratory 
Table 4. - Association between spirometric lung function and proportion of days with respiratory symptoms present during a 2-3-month follow-up among children with chronic respiratory symptoms. Odds ratios (OR) and $95 \%$ confidence intervals (CI) adjusted for age, sex, study centre, atopy, and symptom status (having asthma or not)

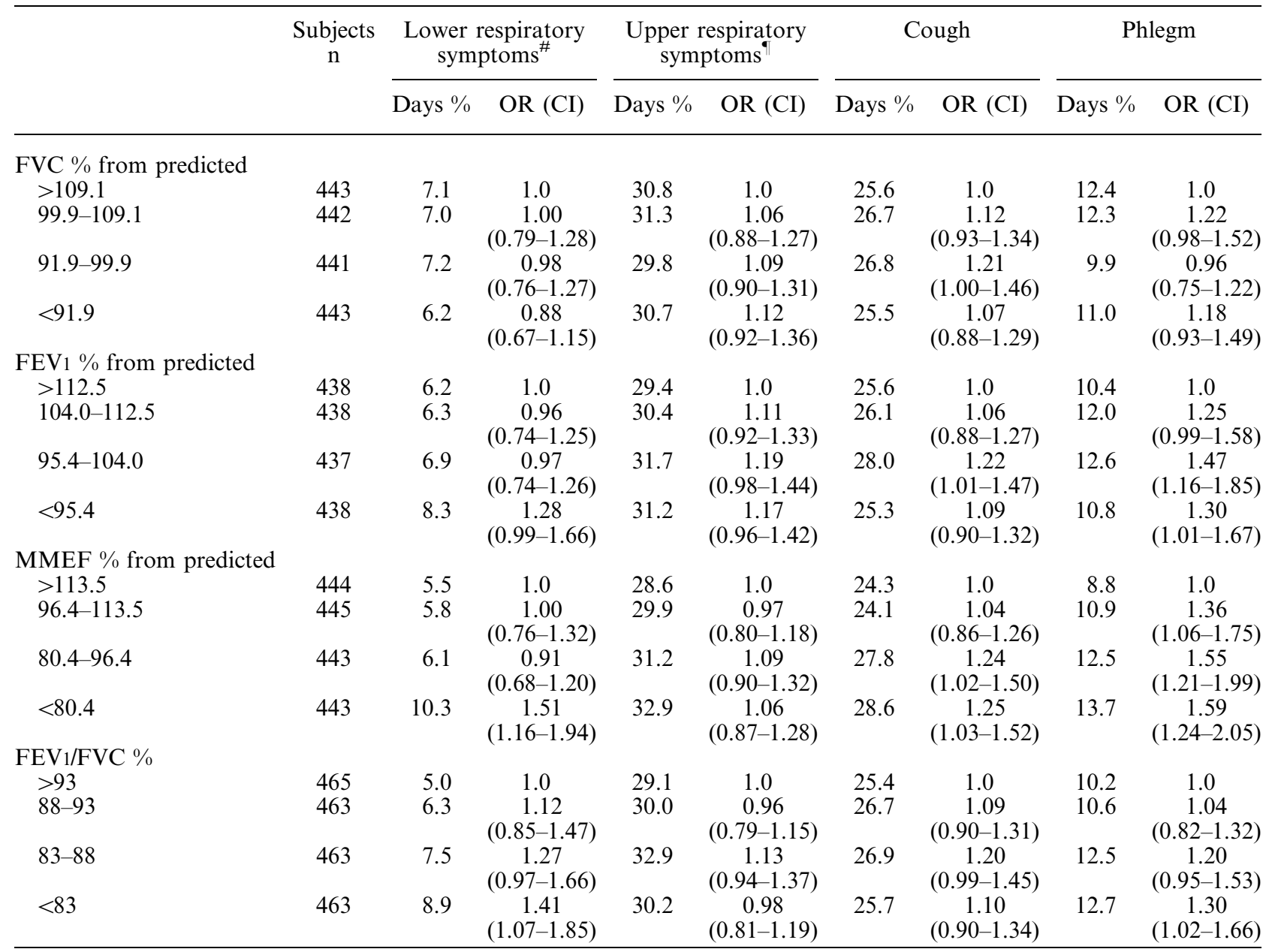

FVC: forced vital capacity; FEV1: forced expiratory volume in one second; MMEF: maximal mid-expiratory flow. ${ }^{\#}$ : shortness of breath, wheeze, or attacks of shortness of breath with wheeze; ${ }^{\natural}$ : stuffed/runny nose, sore throat.

tract symptoms, compared with cough as observed in the present study. Furthermore, unlike this study no interaction between atopy and wheeze was shown.

In the subject selection phase of the study, one-half of the children asked, agreed to participate. This is a little less than in the follow-up study of PATTEMORE et al. [2] in which the response was $62 \%$. It is possible that children, who had had more respiratory symptoms, would have been more likely to participate in the study. However, this selection would have led to more symptomatic children in all groups. Therefore, it is unlikely that the initial selection of subjects would have led to overestimation of the effects. In addition, if children with less severe chronic respiratory symptoms, e.g. cough alone, were less motivated to fill in the diary when free of symptoms, the proportion of days with acute respiratory symptoms would have been overestimated. This would lead to attenuation in the difference between children with asthma and with cough alone. In the present study, this is not likely. A child had to have $>60 \%$ of the days with valid data to be included in the analyses. Moreover, there was no difference in the total number of reporting days between children having asthma and children with cough alone.

Atopy, and especially a positive reaction to house dust mite and cat were significantly associated with the occurrence of lower respiratory symptoms. These results are supported by previous studies. In their study among children with cough or wheeze, ClougH et al. [1] demonstrated that when controlling for the symptom of wheeze, atopy was associated with a significantly greater proportion of days with symptoms than the absence of atopy, during a follow-up over a year. HENDERSON et al. [11] examined correlates of recent wheezing episodes in a case-control study among children. In that study, sensitization to house dust mite was consistently associated with recurrent wheezing episodes, with an OR of 5.2 (95\% CI: 3.0-9.0), whereas no evidence that pollen allergy contributed significantly to susceptibility to recurrent wheezing episodes was provided.

Previously, it has been stated that sensitivity to house dust mite and to cat dander is closely associated 
with current asthma in children, whereas grass sensitivity is not a significant independent risk factor for asthma [12]. This was further supported by the present study. These results confirm the important role indoor allergens play in the occurrence of asthmatic symptoms. However, since this study was confined to the winter time, when children were little exposed to pollen, a role for pollen in the occurrence of acute respiratory symptoms cannot be ruled out.

There was no clear pattern in the association between the level of FVC and the occurrence of acute respiratory symptoms. A reduced level in FEV1 was positively associated with the occurrence of respiratory symptoms, but was significant only with the occurrence of phlegm. A low level of FEV1/FVC was significantly associated with lower respiratory symptoms as well as phlegm. Conversely, a reduced level of MMEF was significantly associated with lower respiratory symptoms, cough and phlegm. This finding together with the previous results, in which a reduced level of MMEF was closely associated with asthmatic symptoms, positive reactions to indoor allergens, and a greater PEF variability, supports MMEF as a sensitive parameter of airway obstruction [13]. MMEF is effort independent and measures flow predominantly in the peripheral airways, whereas FEV1 measures airflow predominantly in the central airway. Therefore, MMEF might be reduced while asymptomatic or in an earlier stage than FEV1.

It is noteworthy that in addition to the level of lung function, positive reactions to house dust mite and cat, and a doctor-diagnosis of asthma with symptoms in the past 12 months were also strongly associated with phlegm in this study. Phlegm is not a classical asthmatic symptom, but clearly in this study, it responds to the same risk factors as more traditional symptoms like wheezing.

The present multicentre study is the first focused on associations between chronic respiratory symptoms, skin test results and lung function, and acute respiratory morbidity in different European regions. In all four regions, the associations between chronic respiratory symptoms, atopy, lung function and acute respiratory morbidity were similar among symptomatic children. To conclude, asthmatic symptoms (reported in a questionnaire), atopy (especially a positive reaction to house dust mite and cat), and a reduced level of maximal mid-expiratory flow were associated with the occurrence of acute respiratory symptoms specifically lower respiratory symptoms, during the 2-3-month follow-up.

\section{References}

1. Clough JB, Williams JD, Holgate ST. Effect of atopy on the natural history of symptoms, peak expiratory flow and bronchial responsiveness in 7- and 8-year-old children with cough and wheeze. A 12-month longitudinal study. Am Rev Respir Dis 1991; 143: 755-760.

2. Pattemore PK, Lampe FC, Smith S, Clough JB, Holgate ST, Johnston SL. Asthma survey items as predictors of respiratory problems in children $2 \mathrm{yrs}$ later: a longitudinal study. Eur Respir J 1999; 14: 650658.

3. Timonen KL, Nielsen J, Schwartz J, et al. Chronic respiratory symptoms, skin test results and lung function as predictors of peak flow variability. $\mathrm{Am}$ J Respir Crit Care Med 1997; 156: 776-782.

4. Anonymous. Effects of short-term changes in urban air pollution on the respiratory health of children with chronic respiratory symptoms. In: Brunekreef $\mathrm{B}$, ed. Study procedures for collaborative study funded by the Commission of the European Communities in the framework of the "ENVIRONMENT" RDT Programme. Wageningen Agricultural University, 1993.

5. Roemer W, Hoek G, Brunekreef B, et al. Effect of short-term changes in urban air pollution on the respiratory health of children with chronic respiratory symptoms: the PEACE project: Introduction. Eur Respir Rev 1998; 8: 4-11.

6. Quanjer PH, Tammeling GJ, Cotes JE, Pedersen OF, Peslin R, Yernault JC. Lung volumes and forced ventilatory flows. Report Working Party, Standardization of lung function tests, European Community for Coal and Steel, Official statement of the European Respiratory Society. Eur Respir J 1993; 6: Suppl. 16, 5-40.

7. Quanjer PH, Stocks J, Polgar G, Wise M, Karlberg J, Borsboom G. Compilation of reference values for lung function measurements in children. Eur Respir J 1989; 2: Suppl. 4, 184s-261s.

8. SAS Institute Inc. In: SAS7 Technical Report P-243, SAS/STAT7 Software: The GENMOD Procedure, Release 6.09. Caty, NC, US SAS Institute Inc., 1993; p. 88.

9. Peat JK, Toelle BG, Salome CM, Woolcock AJ. Predictive nature of bronchial responsiveness and respiratory symptoms in a one year cohort study of Sydney schoolchildren. Eur Respir J 1993; 6: 662-669.

10. Weiss ST, Tager IB, Speizer FE, Rosner B. Persistent wheeze. Its relation to respiratory illness, cigarette smoking, and level of pulmonary function in a population sample of children. Am Rev Respir Dis 1980; 122: 697-707.

11. Henderson FW, Henry MM, Ivins SS, et al. Correlates of recurrent wheezing in school-age children. Am J Respir Crit Care Med 1995; 151: 1786-1793.

12. Sears MR, Herbison GP, Holdaway MD, Hewitt CJ, Flannery EM, Silva PA. The relative risks of sensitivity to grass pollen, house dust mite and cat dander in the development of childhood asthma. Clin Exp Allergy 1988; 19: 419-424.

13. Lebecque P, Kiakulanda P, Coates AL. Spirometry in the asthmatic child: is FEF25-75 a more sensitive test than FEV1/FVC? Pediatr Pulmonol 1993; 16: 19-22. 